\title{
Artesunate versus Quinine in the Treatment of Severe Plasmodium falciparum Malaria at North Eastern of Democratic Republic of Congo: Parasites and Fever Clearance
}

\author{
Ngbonda ND, Alworonga JO, Mashako MR*, Batoko BL, Falay D, Tebandite EK, Muyobela V, Apio N, Nkinamubanzi M and Mande G \\ Department of Pediatrics, Faculty of Medicine and Pharmacy, University of Kisangani, Democratic Republic of the Congo \\ "Corresponding author: Mashako MR, Department of Pediatrics, Faculty of Medicine and Pharmacy, University of Kisangani, Democratic Republic of the Congo, Tel: \\ +243994 11 9595; E-mail: manymashako@gmail.com
}

Received date: September 09, 2018; Accepted date: October 11, 2018; Published date: October 16, 2018

Copyright: (C2018 Ngbonda ND, et al. This is an open-access article distributed under the terms of the Creative Commons Attribution License, which permits unrestricted use, distribution, and reproduction in any medium, provided the original author and source are credited.

\begin{abstract}
Severe malaria is one of the leading causes of death in sub-Saharan African countries and Artesunate is the firstline choice recommended treatment by the World Health Organization. The objective of this study was to identify biological and clinical advantages of Artesunate compared to Quinine in the treatment of severe malaria in children. This study was a randomized and analytical study focused on children admitted to Pediatric Hospital Center Village of Kisangani with severe falciparum malaria, from January 1, 2015 to December 31, 2017. We assigned individuals children intravenous Artesunate $2.4 \mathrm{mg} / \mathrm{kg}$ given as a bolus $(\mathrm{n}=34)$ at $0,12,24$ hours and then daily or Quinine 20 $\mathrm{mg} / \mathrm{kg}$ infused in 5 or $10 \%$ Dextrose over 4 hours than $10 \mathrm{mg} / \mathrm{kg}$ infused every 8 hours $(\mathrm{n}=83)$. During our study period, a total of 117 children were included in the study. 34 were treated with Artesunate while 83 were treated with Quinine. The higher malaria parasites clearance average 1063174 Parasites/ $\mu \mathrm{L}(971$ Parasites/ $\mu \mathrm{L}-1563400$ Parasites/ $\mu \mathrm{L}$ ) concerned the preschool age. The malaria parasites clearance on 12 hours after administration of Artesunate was similar $(79.1 \%)$ compared with $79.1 \%$ clearance obtained by using quinine. The fever clearance of children treated with Artesunate and Quinine was higher in the Artesunate group (91.2\%) than in the Quinine group $(88 \%)$ on 12 hours with significant statistic difference. This study concluded that Artesunate and Quinine present a similar clinic and biologic efficiency.
\end{abstract}

Keywords: Efficiency; Malaria; Antipaludic

\section{Introduction}

Severe malaria is one of the medical emergencies in endemic countries where, if it's not treated; results in $100 \%$ mortality [1]. Malaria is a major morbidity and mortality in the world [2]. In 2016 approximately 1.2 billion people in the world were exposed at high-risk malaria; 216 million cases of malaria globally estimated; 445000 deaths from malaria globally compared to 446000 estimated deaths in 2015. African region accounted for $91 \%$ of all malaria in 2016. Fifteen countries accounted for $80 \%$ of global malaria deaths in 2016. All of these countries are in sub-Saharan Africa except India [3] Plasmodium falciparum is the most prevalent malaria parasite on the African continent and it's responsible for most malaria-related deaths globally [4]. Malaria is one of the most common childhood diseases and a major obstacle for economic and human development in subSaharan Africa. It's a leading cause of child mortality and constitutes the main cause of in-patients' admission in Pediatric wards [5]. Severe malaria causes an estimated 1.24 million deaths every year mostly in children in sub-Saharan Africa [6-8]. The World Organization (WHO) currently recommends parenteral Artesunate as the drug of choice in the treatment of severe malaria in children and Quinine as the second line drug [9-14]. The Democratic Republic of Congo (DRC), endemic country for malaria has the highest severe malaria burden in the world. All people are exposing at risk of malaria, 97\% living in stable transmission areas. We note three species of malaria plasmodium: falciparum, ovale and malariae [15]. Hence 2012, the National Malaria Control Program (NMCP) of the DRC adopted WHO severe malaria treatment guidelines and included injectable Artesunate in the national strategic plan [2]. Few published data exist on intravenous Artesunate in the treatment of severe malaria in DRC and to our knowledge, no study on treatment of severe malaria in children has been conducted in Kisangani at North-Eastern of DRC. The objective of this study is to compare the malaria parasite and fever clearance advantages of Artesunate versus Quinine injectable in the treatment of severe malaria in children and evaluate parasite clearance and fever kinetics.

\section{Materials and Methods}

\section{Study area and duration}

This study was conducted from January 1, 2015 to December 31, 2017, at the Pediatric Hospital Center Village of Kisangani, located in the North- Eastern of Democratic Republic of Congo. This is a heavily malaria-infected area. The centre was chosen because it is the only pediatric health facility the highest referral centre and also has better Pediatric service in the state (Figure 1).

Participants: Patients were included in the study were older than 6 months to 15 years presenting with one or more general danger signs of severe or complicated malaria based on the WHO criteria of severe malaria [16] and had a positive rapid diagnostic test (RDT) for Plasmodium falciparum (SD Biotine Malaria Antigen P/f Pan Standard Diagnostic) and positive Giemsa-Stained thick blood smear on admission. The eligible patients were randomly assigned to treatment with either intravenous Artesunate or Quinine. The first group of children $(\mathrm{n}=34)$ received $2.4 \mathrm{mg}$ body weight of intravenous Artesunate given at $\mathrm{H} 0, \mathrm{H} 12 ; \mathrm{H} 24$. 
Citation: Ngbonda ND, Alworonga JO, Mashako MR, Batoko BL, Falay D, et al. (2018) Artesunate versus Quinine in the Treatment of Severe Plasmodium falciparum Malaria at North Eastern of Democratic Republic of Congo: Parasites and Fever Clearance. J Clin Exp Pharmacol 8: 253. doi:10.4172/2161-1459.1000253

Page 2 of 5

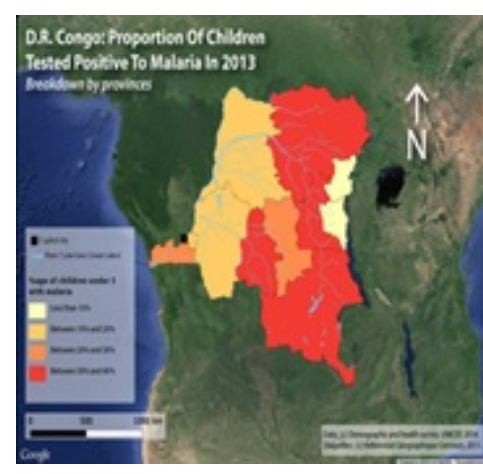

Figure 1: Map of the study site.

The second group children $(\mathrm{n}=83)$ received three doses of Quinine infusion $20 \mathrm{mg} / \mathrm{kg}$ body weight over 4 hours every 8 hours than 10 $\mathrm{mg} / \mathrm{kg}$ body weight every 8 hours. Quinine regimes were diluted in 10 $\mathrm{ml} / \mathrm{kg}$ body weight of $5 \%$ or $10 \%$ dextrose. Oral antimalarial Artemether- Lumefantrine was prescribed for 3 days to complete the Artesunate treatment and oral Quinine at $10 \mathrm{mg} / \mathrm{kg}$ three times a day for 5 days to complete Quinine parenteral treatment.

Patients were excluded if they had a known serious adverse reaction to Quinine and for Artemisinin derivatives; patient without any manifestations of severe malaria; patients with severe malnutrition; children below 6 months and those above 15 years were not included.

Variables: The clinical outcome variables were fever clearance time from the onset of treatment until normalization temperature down to $37.5^{\circ} \mathrm{C}$. The body temperature was taken to the electronic thermometer in respecting carefully the procedure of taking pediatric temperature [17]. The biological outcome variables were parasite clearance time from the onset of treatment to the time of the first of two negatives blood smears.

Parasitological methods: Thick and thin films were prepared and stained with $10 \%$ Giemsa and the parasite counts were obtained by counting the number of asexual parasites per 200 leukocytes, assuming a leukocytes count of 8000 leukocytes/ $\mu \mathrm{L}$ or thick films per 1000 red blood cells for thin films. Blood films were considered negative if no parasites were detected in 100 oil immersion fields of a thick blood film. At presentation, $5 \mathrm{ml}$ of venous blood samples were taken for a completed blood count. Was systematically précised the density parasite at Hour 0 (H0), Hour 12 (H12); Hour 24 (H24) and Hour 36 (H36) for every patient. The rapid test of paludism diagnostic used was on the bases of antigens of Plasmodium falciparum: Histidine Rich Protein II and PLDH (Lactate Dehydrogen), this test was systematically done to all patients from the admission [16-18].

\section{Data collection and treatment}

A survey form has helped us in the collection of different variables in this study which were the age, sex, clinical signs and biologic signs. The data obtained were analyzed with the SPSS 20.0 and Excel 2010 software.

\section{Ethical considerations}

Necessary clearance was obtained from the Village Pediatric Hospital Center authorities and Hospital ethics committee and written consent were also obtained from the children's caretakers. Moreover confidentiality was maintained during data collection and processing and procedures did not endanger or have adverse effects on the patients.

\section{Data and statistical analysis}

Data missing at random was dealt with by partial case-wise deletion. Statistical analysis was performed using SPSS statistics 20.0. Levels of parasitaemia were log-transformed before analysis. The significance of differences in prevalence was explored using Pearson's Chi-square or Fisher's Exact test whereas differences in group means were assessed using student's tests. A difference giving a P-value $<0.05$ was considered statistically significant.

\section{Results}

During our study period, a total of 117 children were included in the study. 34 were treated with Artesunate while 83 were treated with Quinine. Males was $66(56.4 \%)$ and females 51 (43.6\%) without significant difference $\mathrm{X} 2=3.918, \mathrm{Ddl}=1 ; \mathrm{p}>0.05$.

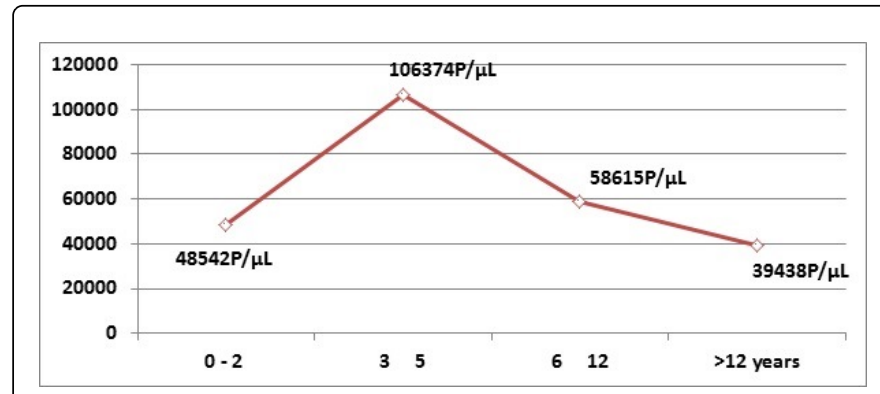

Figure 2: Distribution of parasitary density according to age.

It clearly appear (Figure 2) that high malaria parasites clearance average 106374 Parasites/ $\mu \mathrm{L}$ (971 Parasites/ $\mu \mathrm{L}-1563400$ Parasites $/ \mu \mathrm{L}$ ) concerned the preschool age.

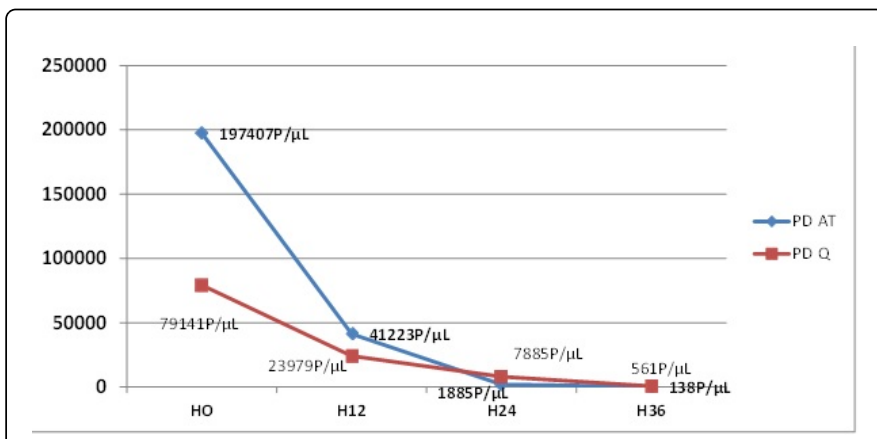

Figure 3: Malaria parasite clearance time.

The malaria parasites clearance (Figure 3), on 12 hours after administration of Artesunate was similar (79.1\%) compared with $79.1 \%$ clearance obtained by using quinine, However, parasitaemia clearance was $99.7 \%$ with Artesunate and $99.8 \%$ with quinine one 36 hours without significant statistic difference (Figure 4). 
Citation: Ngbonda ND, Alworonga JO, Mashako MR, Batoko BL, Falay D, et al. (2018) Artesunate versus Quinine in the Treatment of Severe Plasmodium falciparum Malaria at North Eastern of Democratic Republic of Congo: Parasites and Fever Clearance. J Clin Exp Pharmacol 8: 253. doi:10.4172/2161-1459.1000253

Page 3 of 5

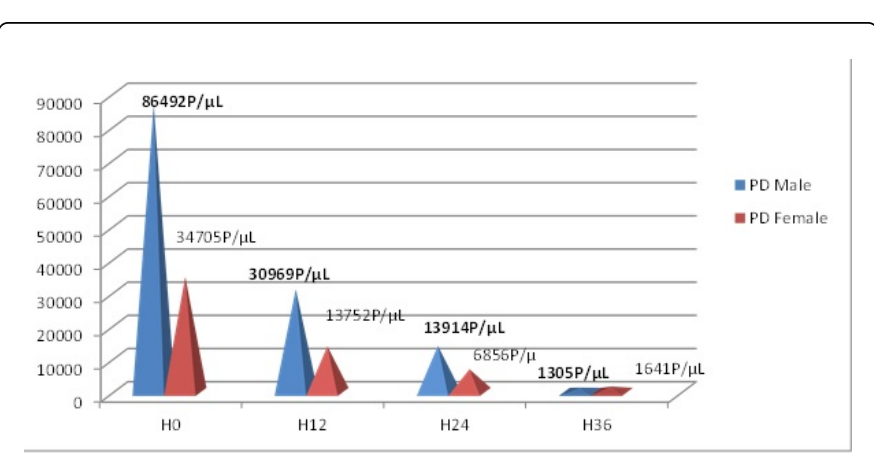

Figure 4: Distribution and evolution of parasites density according to gender.
In our study males was 66 (56.4) and females 51 (43.6) without significant difference $\mathrm{X} 2=3.918, \mathrm{Ddl}=1 ; \mathrm{p}>0.05$ and boys presented higher malaria parasites clearance average of 864924 Parasites $/ \mu \mathrm{L}$ (2961 Parasites/ $\mu \mathrm{L}-1563400$ Parasites/ $\mu \mathrm{L}$ ) (H0) compared to girls admitted who had a malaria parasites clearance average of 34705 Parasites $/ \mu \mathrm{L}$ (971 Parasites/ $\mu \mathrm{L}-528700$ Parasites/ $\mu \mathrm{L}$ ). Malaria parasites clearance decrease in a proportional way to 12,24 and 36 hours after administration of doses of Artesunate and Quinine (Table 1).

The fever clearance of children treated with Artesunate and Quinine was higher in the Artesunate group (91.2\%) than in the Quinine group $(88 \%)$ on 12 hours with significant statistic difference $\mathrm{X} 2=0.254$, $\mathrm{Ddl}=1 ; \mathrm{p}<0.05$ and was $100 \%$ in both drug group on 48 hours later.

\begin{tabular}{|c|c|c|c|c|}
\hline \multirow[t]{2}{*}{ Hours } & \multicolumn{3}{|c|}{ Artesunate } & \multirow{2}{*}{$\begin{array}{l}\text { Quinine } \\
<=37.5^{\circ} \mathrm{C}\end{array}$} \\
\hline & $>37.5^{\circ} \mathrm{C}$ & $<=37.5^{\circ} \mathrm{C}$ & $>37.5^{\circ} \mathrm{C}$ & \\
\hline & $n=34$ & $n=34$ & $n=83$ & $n=83$ \\
\hline HO & $34(100)$ & $0(0.00)$ & $83(100)$ & $0(0.00)$ \\
\hline $\mathrm{H} 12$ & $03(08.8)$ & 31 (91.2) & $10(12.0)$ & $73(88,0)$ \\
\hline $\mathrm{H} 24$ & $02(05.9)$ & 33 (94.1) & 08 (09.6) & 75 (90.4) \\
\hline $\mathrm{H} 36$ & $01(02.9)$ & 33 (97.1) & $03(03.6)$ & $80(96.4)$ \\
\hline $\mathrm{H} 48$ & $0(0.00)$ & $34(100)$ & $0(0.00)$ & $83(100)$ \\
\hline
\end{tabular}

Table 1: Fever clearance.

\section{Discussion}

Malaria is a focal disease in the North-Eastern of Democratic Republic of Congo, influenced by several local ecological, social factors; climatic variability [19] and the genetic diversity of Plasmodium falciparum [20]. The objective of this study was to compare biologic and clinical advantages of Artesunate versus Quinine injectable in the treatment of severe malaria in children, also evaluated parasite clearance and fever kinetics.

\section{Distribution of parasitary density according to age}

It clearly appears in our study (Figure 2), that higher parasite malaria density average 106374 Parasites/ $\mu \mathrm{L}$ (971 Parasites/ $\mu \mathrm{L}-1563400$ Parasites $/ \mu \mathrm{L}$ ) concerned the preschool age. This category of children have palustre immunity progressively acquired and relative low IgG responses active in endemicity palustre stable zone as the Democratic Republic of Congo. [18]. This result coincides with Manoj et al. funding, who observed the dependent age variation of malaria attack, parasite prevalence and density levels in preschool age at Jharkhand in India [21]. In our country, this higher malaria parasite density could be explained by the marginal utilization of insecticide impregnate mosquito net long duration (IIMLD), the possibility of the new vectors; immuno-genetic factor not précised in our study and environmental factors.

\section{The parasite clearance}

Three independent processes contribute to the clearance of malaria parasites from the peripheral blood circulations: Host-defence mechanisms; anti-malarial drug as Artesunate or Quinine effects and sequestration $[22,23]$. Rapid malaria parasite clearance in our study (Figure 2), on 12 hours was similar (79.1\%) both in Artesunate and Quinine groups. Parasite clearance time was also not found to be different between Artesunate and Quinine in the treatment of severe Plasmodium falciparum malaria in children. Eltahir et al. was found the same result in Central Sudan [24] however, Ndour et al. Observed rapid malaria parasite clearance with Artesunate in the treatment of severe malaria in Malian children [25]. Artemisinin derivatives and its derivatives are first-line treatment for severe and uncomplicated Plasmodium falciparum worldwide. Artemisinin and derivatives are typical schizontocides for all forms of Plasmodium; also they act on the gametocytes of some plasmodia by delaying their formation and destroying them in the blood. These two pharmacodynamics effects, which are not achieved by Quinine, are explained advantages of Artesunate to reduce rapidly malaria parasite density [26,27].

\section{Distribution and evolution of malaria parasites density according to gender}

In our study males was $66(56.4 \%)$ and females 51(43.6\%) without significant difference $\mathrm{X} 2=3.918, \mathrm{Ddl}=1 ; \mathrm{p}>0.05$. Others authors get similar results $[21,28]$. According to gender and malaria parasites density, boys presented higher malaria parasites density average of 
Citation: Ngbonda ND, Alworonga JO, Mashako MR, Batoko BL, Falay D, et al. (2018) Artesunate versus Quinine in the Treatment of Severe Plasmodium falciparum Malaria at North Eastern of Democratic Republic of Congo: Parasites and Fever Clearance. J Clin Exp Pharmacol 8: 253. doi:10.4172/2161-1459.1000253

Page 4 of 5

864924 Parasites $/ \mu \mathrm{L}$ (2961 Parasites/ $\mu \mathrm{L}-1563400$ Parasites $/ \mu \mathrm{L}$ ) at admission compared to girls admitted who had a malaria parasites density average of 34705 Parasites/ $\mu \mathrm{L}$ (971 Parasites/ $\mu \mathrm{L}-528700$ Parasites $/ \mu \mathrm{L})$. Parasites density decrease in a proportional way to 12,24 and 36 hours after administration doses of Artesunate and Quinine both in male and females' gender. Males and females differ in their ability to cope with infection, beyond physiological mechanisms, immune differences from an adaptive point of view in relation to sexspecific reproductive strategies; genotype and phenotype of pathogens. Generally, male traits exhibit large sensitivity to extrinsic changes than female $[1,2]$.

\section{Fever clearance}

Artesunate is more effective than Quinine in term of fever clearance in the treatment of Plasmodium falciparum malaria in the NorthEastern of the Democratic Republic of Congo. In Artesunate group fever clearance was observed in (91.2\%) than in the Quinine group $(88.0 \%)$ on 12 hours after treatment with significant statistic difference $\mathrm{X} 2=0.254, \mathrm{Ddl}=1 \mathrm{p}<0.05$ and the clearance fever were $100 \%$ in both drug groups on 48 hours later. Tajeldin $\mathrm{M}$ et al, get a similar result in Sudan at Kassala Hospital [29].

\section{Conclusion}

The current study showed that Artesunate and Quinine are comparable alternatives in the treatment of severe malaria in children. Artesunate is as effective as Quinine in terms of parasite clearance in the North-Eastern of DRC. The fever clearance of children treated with Artesunate and Quinine is higher in the Artesunate group (91.2\%) than in the Quinine group (88\%) on 12 hours with significant statistic difference $\mathrm{X} 2=0.254, \mathrm{Ddl}=1 ; \mathrm{p}<0.05$. However, we recommend permanent surveillance of malaria parasite charge at look different molecules of Artesunate proposed on market, also the observance of individual and collective prophylactic measures mainly at the children in preschool age.

\section{Competing Interests}

The authors declare that they have no competing interests.

\section{Authors' Contributions}

Ngbonda NG conceived the study and all authors participated to collect the data, performed the statistical analysis; wrote the draft of the paper and were involved in critically revising the manuscript for important intellectual content. All authors read and approved the final manuscript.

\section{Acknowledgement}

We thank all the patients and their families for participating in this study.

\section{Financial Support}

This study was supported by authors.

\section{References}

1. Godonou G, Zohoun L, Bognon G, Agossou J, Pandanou C, et al. (2017) Benefits of artesunate versus quinine in the treatment of children with severe malaria at the National University Teaching Hospital of Cotonou. J Ped 7: 156-163.

2. Ferrari G, Ntuku M, Berri C, Tshefu K, Dupare S, et al. (2015) An operational comparative study of quinine and artesunate for the treatment of severe malaria in hospitals and health centers in Democratic Republic of Congo: the MATIAS study. Malar J 14: 226.

3. Noubiap N (2014) Shifting from quinine to artesunateas first-line treatment of severe malaria in children and adults: saving more lives. J Infect Public Health 7: 407-412.

4. World Health Organization, Malaria; The key points: World malaria report 2017. WHO Geneva.

5. Abdallah M, Elmardi A, Elhassan H, Omer B, Elhag S, et al. (2014) Comparison of artesunate and quinine in the treatment of severe Plasmodium falciparum malaria at Kassala Hospital Sudan. J Infect Dev Ctries 8: 611-615.

6. Rasamaelina N, Andrianimaro F, Fenomanana J, Randriamanantany Z, Razafimahefa S, et al. (2018) Epidemiological, clinical and evolutionary profile of severe malaria cases in the intensive care unit of the Tambohobe- Finarantsoa Teaching Hospital. EC Microbiology 14: 78-83.

7. WHO, World Malaria Report. Geneva world Health Organization. 2011.

8. Murray C, Rosenfeld L, Lim S (2012) Global malaria mortality between 1980 and 2010. A systematic analysis. Lancet 379: 413-431.

9. Maka D, Chiabi A, Bolaji O, Mah E, Nguefack S, et al. (2016) Economic evaluation of artesunate and three quinine regimens in the treatment of severe malaria in children at the Ebolowa Regional Hospital-Cameroon: A cost analysis. Malar J 15: 587.

10. WHO, Guidelines for the treatment of Malaria. Geneva world Health Organization. 2010.

11. WHO, Guidelines for the treatment of malaria. Geneva. World Health Organization. 2015.

12. WHO, Guidelines for the treatment of malaria South Africa. 2017.

13. Dondorp A, Nosten F, Stepniewska K, Day N, White N. (2005) Artesunate versus quinine for treatment of severe malaria : A randomised trial. Lancet 366: 717-725.

14. Dondorp A, Fenello C, Hendriksen I, Gomes E, Seni A, et al. (2010) Artesunate versus quinine in treatment of severe falciparum malaria in African children.A open- Label, randomised trial. Lancet 376: 1644-1657.

15. Lubell Y, Riewpaiboon A, Dondorp A, Seidlein L, Mokuolu O, et al. (2011) Cost-effectiveness of parenteral artesunate for treating children with severe, malaria in Subsaharan Africa. Bull world Health Organ 89: 504-512.

16. Verma P, Biswas S, Mohan T, Ali S, Rao DN (2013) Detection of histidine rich protein and lactate dehydrogenase of plasmodium falciparum in malaria using in house reagent. Ind J Med Res 138: 977-987.

17. Houze S (2017) Rapid diagnostic test for malaria Bull Soc Pathol Exot 110: 49-54.

18. Adu-Gyasi D, Kwaku A, Sam N, Amoako S, Dosoo D, et al. (2015) Malaria parasite density estimated with while blood cells count reference value agrees with density estimated with absolute in children less than 5 years in central Ghana. Malaria Res Treat 2015: 8.

19. Laneri K, Paul R, Tall A, Faye J, Fatoumata S, et al. (2018) Buffers effect of climatic variability. PNAS. USA.

20. Sorontou Y, Pakpahan A (2015) Genetic diversity in MSP-1 gene of plasmodium falciparum and its association with malaria severity, parasite density and host factors of asymptomatic and symptomatic patients in Papua, Indonesia. Int J Med Sci Public Health 4: 158-93.

21. Manoj K, Brijesh K, Regis W, Kumud R, Bright A, et al. (2017) Malaria epidemiology in an area of stable transmission in tribal population of Jharkhand, India Malar J 16: 181.

22. White NJ (2017) Malaria parasite clearance. Malar J 16: 1-14.

23. Chang H, Meibalan E, Zelin J, Daniels R, Ezeifula A, et al. (2016) Persistence of plasmodium falciparum parasitemia after Artemisinin, contribution therapy : Evidence from a randomized trial in Uganda. Sci Rep 6: 26330. 
Citation: Ngbonda ND, Alworonga JO, Mashako MR, Batoko BL, Falay D, et al. (2018) Artesunate versus Quinine in the Treatment of Severe Plasmodium falciparum Malaria at North Eastern of Democratic Republic of Congo: Parasites and Fever Clearance. J Clin Exp Pharmacol 8: 253. doi:10.4172/2161-1459.1000253

Page 5 of 5

24. Eltahir H, Omar A, Mohamed A, Adam I (2010) Comparison of artesunate and quinine in the treatment of Sudanese children with severe Plasmodium falciparum malaria. Trans R Soc Trop Med Hyg 104: 684-686.

25. Ndour P, Lopera-Mesa T, Diakité S, Chiang S, Oussama M, et al. (2014) Plasmodium falciparum clearance is rapid and pitting independent in immune Malian children treated with Artesunate for Malaria. J Inf Dis 2: $1-8$.

26. Tajeldin M, Khalid A, Asama H, Mona B, Mousab S, et al. (2014) Comparison of artesunate and quinine in the treatment of severe plasmodium falciparum malaria at Kasala Hospital, Sudan. J Inf Dev Ctries 8: 611-615.
27. Elechi H, Rabasa A, Muhammad F, Garba M, Abubakar G, et al. (2015) Prevalence and pattern of malaria parasitaemia among under five febrile children attending Pediatric outpatient clinic at University of Maiduguri Teaching Hospital. Nigeria J Ped 42: 319-324.

28. Restif O, Amos W (2010) The evolution of sex-specific immune. Proc R Soc B 277: 2247-2255.

29. Esan A, Omisakin C, Titilayoo F, Fasakin K (2014) Evaluation of severity of malaria infection and effect of gender difference on stress induced by malaria parasite infection an effect of anti-malaria drug on stress index. Am J Biol Res 2: 42-46. 